Document downloaded from:

http://hdl.handle.net/10251/122508

This paper must be cited as:

Serrano, J.; Tiseira, A.; García-Cuevas González, LM.; Rodriguez-Usaquen, YT. (2018). Adaptation of a 1-D tool to study transient thermal in turbocharger bearing housing. Applied Thermal Engineering. 134:564-575. https://doi.org/10.1016/j.applthermaleng.2018.01.085

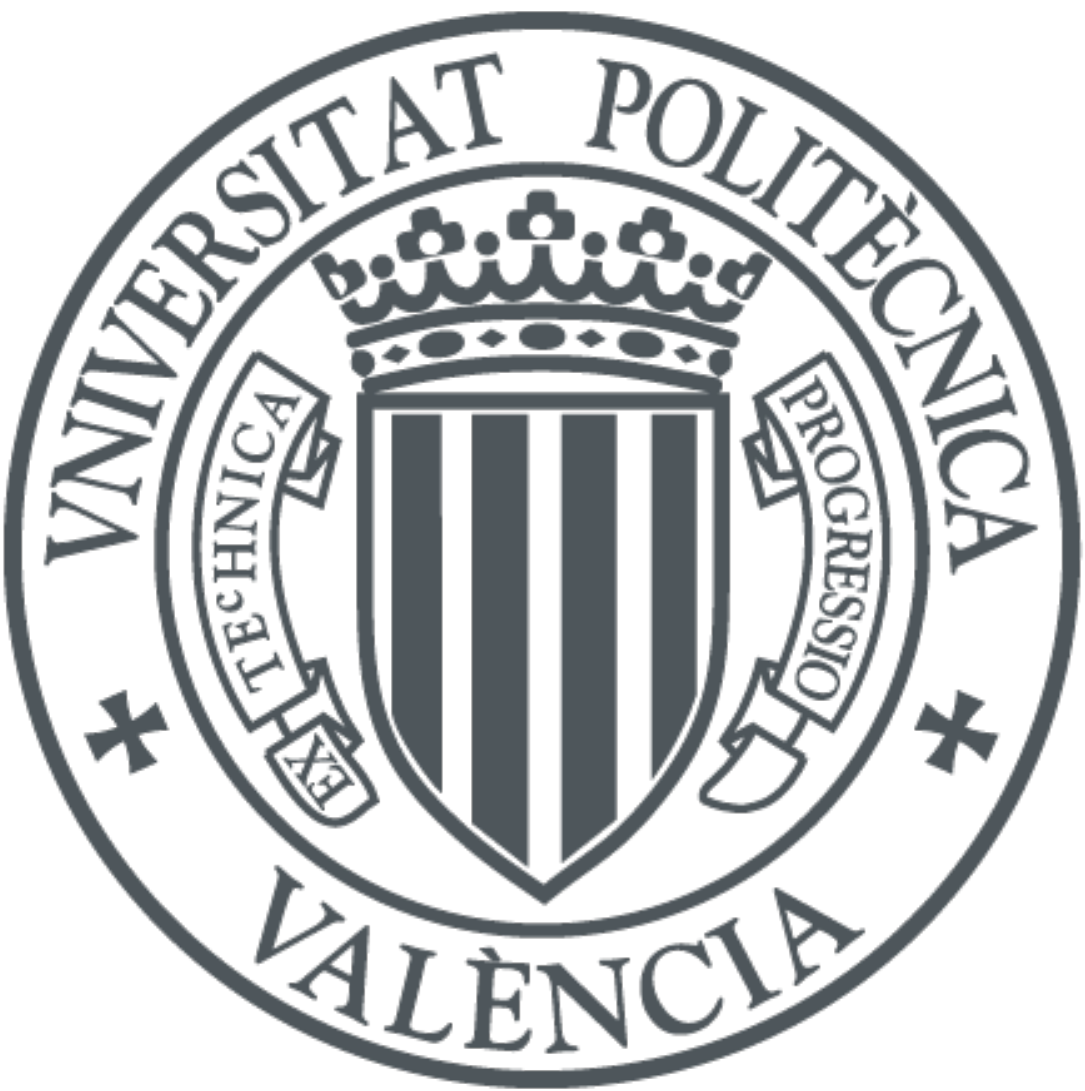

The final publication is available at

https://doi.org/10.1016/j.applthermaleng.2018.01.085

Copyright Elsevier

Additional Information 
Standard article

Corresponding author:

Tatiana Rodriguez, CMT - Motores Térmicos. Universitat Politècnica de València. Camino de Vera, s/n. 46022. Valencia, SPAIN.

Phone: + 34963877650

Fax: + 34963877659

Email: yulrodu1@mot.upv.es

\title{
Adaptation of a 1-D tool to study transient thermal in turbocharger bearing housing
}

\author{
José Ramón Serrano, Andrés Tiseira, Luis Miguel García-Cuevas \\ and Tatiana Rodríguez Usaquén
}

CMT_-Motores Térmicos, Universitat Politècnica de València, Camino de Vera s/n, 46022 Valencia, Spain

\section{Abstract}

The heat transfer model can be used in a one-dimensional (1-D) engine simulation. When the engine speed is reduced to zero, the codes have been upgraded to calculate transient turbocharger thermal conditions. The turbocharger model has been used as an external plugin. Analysis of the temperature evolution at different parts of the turbocharger is done by using a hot spot engine cycle. A turbocharger bypassing strategy is done by means of a 9 bypass valve system. By using this method, instabilities can be found in the binary onoff state of an engine.

During engine hot-stops, the lack of oil flow inside the turbocharger makes the trapped oil in the bearings burnt as the turbine housing exchanges heat with the central housing. Coke formation can appear and produce big reductions in turbocharger endurance, as bearings clogged and damage the shaft. Several strategies can be used in order to minimize possibilities of coke formation, including an increase in the turbocharger cooling during normal operation and the use of electrically-driven pumps acting after the engine is shut down. These strategies can be simulated in acceptable calculation times thanks to modelling strategy proposed in this paper.

The presented methodology allows a detailed study of the temperature rise of the central housing of an automotive turbocharger after a hot-stop process, simulating several combinations of cooling strategies in order to find the optimum one in terms of minimising extra energy consumption per $\mathrm{K}$ of housing temperature reduction. 


\section{Highlights}

$>$ Thermal sensitivity is measured in the turbocharger in regards to a onedimensional engine.

$>$ A visual aid, such as a model, can help depict the evolution of thermal theory.

$>$ The behaviour of a turbocharger in a hot stop is affected by such diverse cooling strategies.

$>$ A coke phenomenon in the lubricating circuit affects turbocharger efficiency and durability.

$>$ High temperatures that occur within a turbocharger produce problems such as clogged bearing systems and damaged shafts.

\section{Keywords}

Turbocharger, one-dimensional model, engine simulation code, heat transfer, engine hot stop, oil coke.

\section{Introduction}

Nowadays, most automotive engines have a turbocharging system. The turbocharging system increases the energy efficiency of the engine [1]. The system has been used for a long time in the boost of automotive engines [2] and each of the elements that make up the turbocharger has been gradually improved. Policies of pollutant, such as NOx, fuel consumption and noise have influenced its development. The system is an important piece for the new generation of engines that must comply with the EURO6 European standard in force from 2015 [3].

In order to ensure that the system does not experience any mechanical failures or loss of efficiency, it is important to study which engine operating conditions could produce the highest failing rate.

Common failing conditions in turbochargers are mostly achieve due to oil contamination which results in little particles of debris that engine parts have shed; thrust failure turning the boost up; excessive exhaust gas temperatures, oil delay, impact damage in compressor or turbine wheels. The works focused on the oil behaviour conclude that the engine hot stop and carbon build up failure produces blockage in the system of bearings [4].

Tight tolerances in the turbocharger does not take much for bits of debris to block oil ways and reduce the oil flow [5]. High boost pressures and high rotational speeds make the material will shred. Excessive exhaust gas temperatures can range from a severely pitted turbine wheel to a bent turbine shaft, affecting other areas of the engine and leaving bits of aluminium piston melted onto the turbine wheel.

Some signs for the oil delay failure are that the material can wipe out all over the shaft and get blue due to a high temperature which has been built by heat. Failures that cause damage in compressor or turbine wheel [6] can be produced by anything from dust entering to large 
pieces of debris in the air system from previous failures or in turbine wheel by bits coming from the combustion chamber or the manifold itself.

Carbon builds up due to lack of servicing and poor quality oils, which results in a gradual build-up of sludge in both the sump and all oil galleries of the engine. Inside the turbocharger there are some of the narrowest oil ways, some as small as $1 \mathrm{~mm}$ in diameter, and when they become blocked failure can occur [4].

Several research studies about turbocharger endurance and loss of efficiency have been found in the literature. Some works focus their study on aerodynamic or acoustic phenomena, looking for flow disturbance sources in either the compressor or the turbine side. Galindo et al. [7], Gravdahl et al. [8] or Skopil et al [9] argue that the important limitation for the turbocharger operation is the compressor surge phenomena, which may damage and even destruct the turbocharger shaft and wheels.

Galindo et al. [10] studies 1-D heat transfer models for predicting engine transient conditions and improve the thermal response in the turbocharging system. Burke et al. study how the heat transfer influences engine performance calculation showing that heat transfer in the turbine always represents an important part of its enthalpy change, being more relevant in the low torque region [11].

Mechanical and thermal problems are also a typical source of turbocharger damage. Serrano et al. [12] study the robustness of several turbochargers ingestion of different elements such as screws, sand or water with the compressor. An automotive turbocharger shaft can easily achieve rotational speeds higher than $200 \mathrm{krpm}$, and floating or semifloating journal bearings are usually used. Galindo et al. [13] also study the mechanical behaviour of turbochargers with intermittent stops of the lubricating oil flow. The temporal lack of lubrication leads to wear of the bearings and final imbalance of the shaft very quickly. The turbocharger friction losses inside the bearings system is also dependent on the geometry of such bearings $[14,15]$, so even when wearing might not finally break the turbocharger it could affect its mechanical efficiency.

The oil also serves, as coolant in turbochargers, so oil ducts clogging not only affects the final turbocharger lubrication, but also its capacity to withstand high temperatures. When a turbocharger water cooling circuit exists (mainly in turbochargers for petrol engines), the engine manufacturer has an extra capacity to reduce the risk of thermal damage by adjusting the characteristics of water pump [16].

Evaluation of different heat transfer conditions for the turbocharger external surface is done considering different engine speeds and loads [17].The thermal damage in the turbocharger might be noticed some time after it has been produced. If the oil thermal load is too big, it might degrade and produce coke leading to oil ducts and bearings clogging, thus reducing the oil flow. This reduction in oil flow leads to a loss of bearing loading capabilities and cooling performance, enabling mechanical wear and further thermal damage. A typical situation of oil thermal damage is produced during engine hot-stop, where oil flow is halted. In these cases, the turbine exchanges huge amounts of heat with the central housing as it 
cools down, increasing the temperature of the small amounts of oil trapped inside the turbocharger and producing oil coke [18]. Some of the last tendencies in the automotive industry seeking to reduce the engine fuel consumption and emissions might even generate extra damage in the lubrication system. Such as the case of Start-Stop systems, in which the engine is stopped when it was idle and there was neither oil nor coolant flow in the turbocharger, which might produce oil thermal degradation, and some other effects of reducing oil pumping for improving the engine consumption [19].

This paper presents an adaptation of a 1-D tool to study thermal transient in turbocharger bearing housing by means of a bypass system of 9 valves in order to perform conditions of engine on and off. Thanks to this innovative modelling approach, different strategies for reducing the probability of coke formation have been calculated in acceptable time and discussed. Through a factorial study of four variables at two different levels, the optimum in terms of power consumption and extra $\mathrm{CO} 2$ emissions is selected. The first section presents the turbocharger and engine model management of the hot stop, in which the transient engine cycle and bypassing method implemented for the simulation campaign are described. Also, a comparison of the trends in transient operation between the turbocharger heat transfer model (HTM) and three engine operating points measured in engine test bench under a hot stop engine cycle is evaluated. Finally the last section presents modelling of the cooling strategy employed using coolant and oil pumps with different sizes and the ability to keep them on after engine shutdown and discussion of the results obtained, studying the reduction of the probability of oil damage and coke formation in the bearing system as a starting point for future research studies.

\section{Turbocharger model and engine model management of the hot stop}

As aforementioned, a simulation campaign has been performed computing an engine cycle with some variations in the operation of the oil and coolant pumps feeding the turbocharger. Those have been carried out using GT-POWER ${ }^{\mathrm{TM}}$ engine simulation code, nevertheless in this study the turbocharger model has been implemented as an external plugin and is able to reproduce the thermal evolution of the turbocharger. This turbocharger heat transfer model has been previously validated in steady-state and transient conditions [20,21]. The turbocharger model is able to calculate the main performance variables of the compressor and the turbine and it has the capability of computing the main heat fluxes in the turbocharger, including the metal-to-metal heat flows, the cooling effects of the oil, the oil heating due to friction losses and the coolant and the external heat flows.

The Heat Transfer Model (HTM) is based on the principle of similarity with an electrical circuit [22]. Figure 1 shows the configuration that has been implemented, where 5 metal nodes can be seen. Each of these nodes represents a plane in the turbocharger, being part of a mostly-one-dimensional model. Although mainly one-dimensional, the model also considers the heat transfer to the ambient, oil and coolant. Table 1 shows the description of the different nodes. 


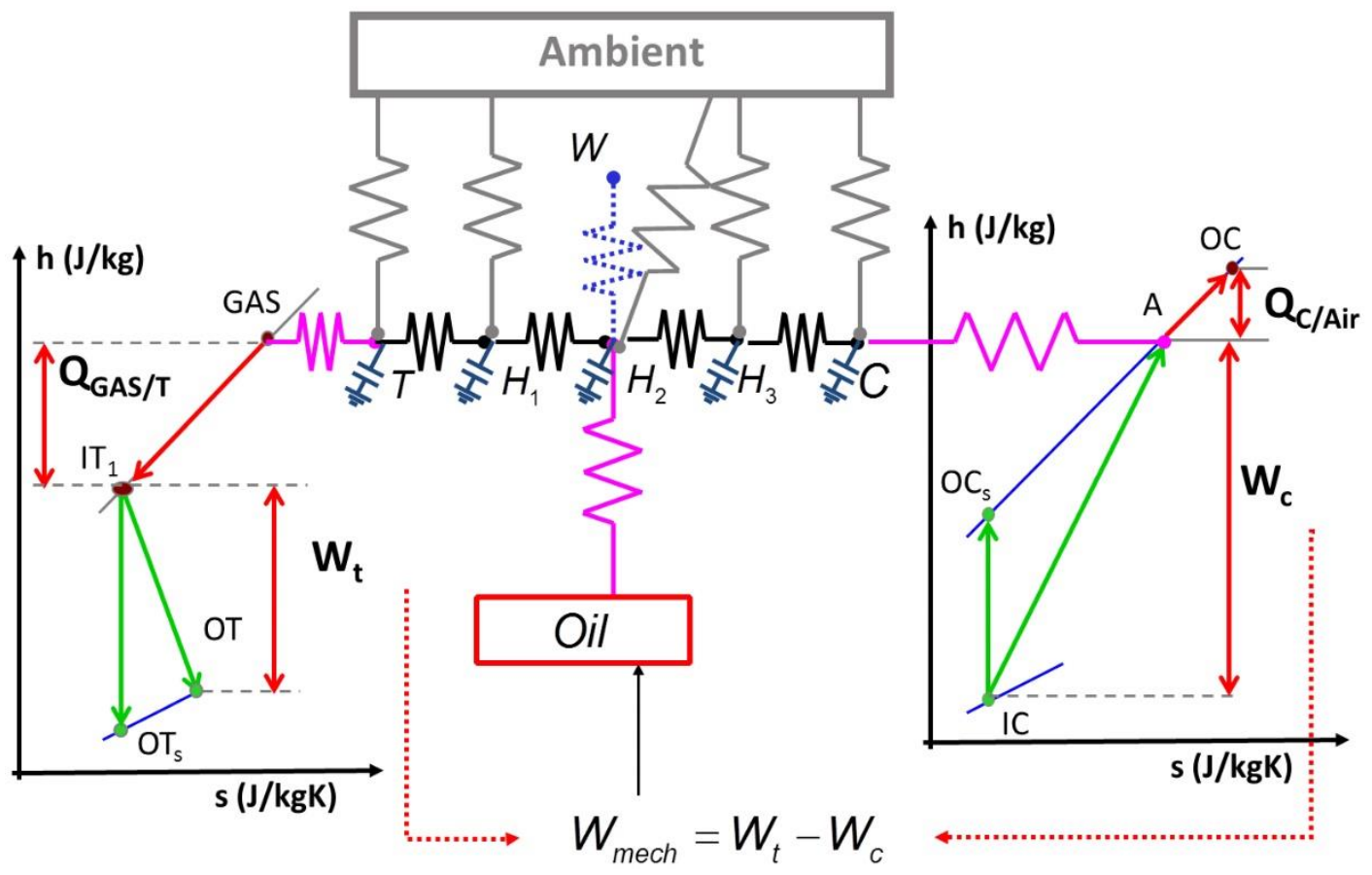

Figure 1. One-dimensional heat transfer model for a turbocharger.

Table 1. Definition of nodes on the turbocharger.

\begin{tabular}{c|l}
\hline $\begin{array}{c}\text { Metal } \\
\text { node }\end{array}$ & \multicolumn{1}{|c}{ Description } \\
\hline $\boldsymbol{T}$ & Turbine housing node \\
\hline $\boldsymbol{H 1}$ & Turbine back plate node \\
\hline $\boldsymbol{H} 2$ & Housing central node \\
\hline $\boldsymbol{H} 3$ & Compressor back plate node \\
\hline $\boldsymbol{C}$ & Compressor housing node \\
\hline
\end{tabular}

The turbocharger heat transfer model includes as data input, the mass flow and temperatures at the compressor outlet, at the turbine inlet, in the lubrication and cooling system; it includes the turbocharger speed, compression and expansion ratio, the ambient velocity and atmospheric pressure. The one-dimensional model is able to calculate the temperature of the metal and predict the mean temperatures of exhaust gas and air as flowing inside the turbocharger. Nowadays, the working temperature of the turbocharging system has increased, reaching values even higher than $1000 \mathrm{C}$ in the turbine side [23]. This has led turbo manufacturers to take into account water cooling and the incorporation of new materials [24]. When the highest temperatures are reached, water-cooling prevents the degradation of oil inside the bearings. As the engine model used is programmed in the commercial gas-dynamics-1D-code GT-POWER ${ }^{\mathrm{TM}}$ it lets modelling each of the most important components and processes of the engine [25]. This simplified model has had an 
extensive validation, using the aforementioned HTM to compute the turbocharger thermal evolution. The results from the validation of the whole engine model, including the turbocharger heat transfer model, showed that the latter reaches similar values to the measurements obtained experimentally [26].

Values of temperature in each part of the turbocharger during the simulations are shown and discussed in the results section.

The method uses an engine cycle over a representative engine operating point for the analysis of temperature evolution at different parts of the turbocharger. The cycle is used to study oil coke formation inside the turbocharger bearings, but it can also be used to study the evolution of other parameters such as temperatures and pressures in different parts of the engine. Automotive companies predefine these cycles in order to ensure that the studied parameters do not exceed some limits which are detrimental for the engine life. Figure 2 shows the simulated end period of a hot stop engine cycle represented in engine power vs time.

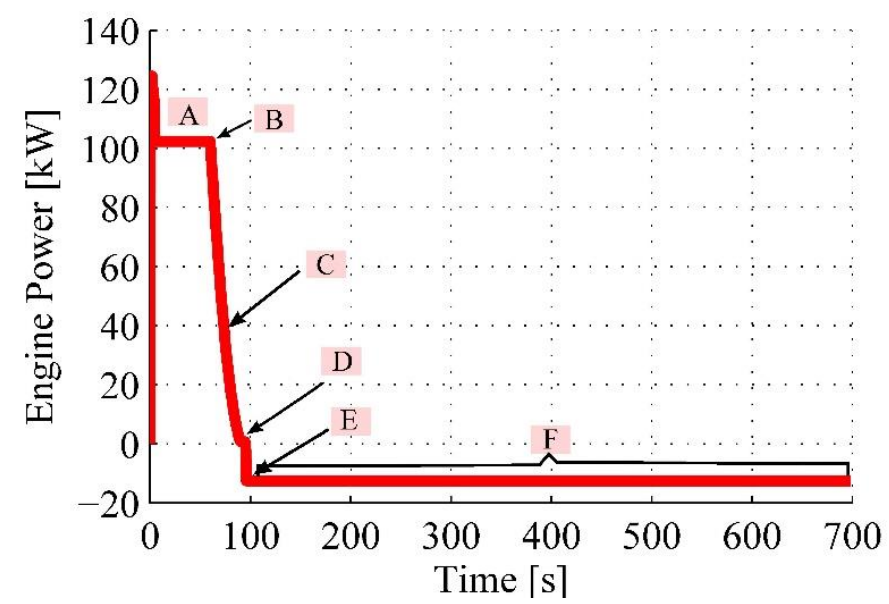

Figure 2. Last part of a hot stop engine cycle

The driving cycle consists of 2 hours of high engine load operation, typical of highway driving conditions, followed by a hot stop. The simulations represent the last 700 seconds of this cycle. The cycle has stationary and transient part. Initially, engine temperatures are stabilized at full load and high speed, typically the speed of $3500 \mathrm{rpm}$ in a Diesel engine, that takes place in the simulation for a shortened period of about 60 seconds (A in figure 2 ), followed by a deceleration phase ( $\mathrm{C}$ in figure 2 ) as function of the operating point, a decreasing speed and load intended for reaching the engine idle conditions is done for 5 seconds (D in figure 2), and finally a quick stop of the engine, where the circulation of water, oil and air through the turbocharger are cut for an allotted period of time that let the turbocharger reach the maximum peaks of temperatures in each section node ( $\mathrm{F}$ in figure 2). This hot-stop cycle produces peak temperatures in the central housing and, thus, in the bearing system. 
For this study the adjustment of both the engine and the turbocharger models during transient hot stop simulations are an additional task for the study. As calculation instabilities were found during engine stops simulation, a turbocharger bypassing strategy is done by means of a system of 9 bypass valves in order to perform conditions of engine on and off; in this way, the thermal evolution of the turbocharger model continues computing when the engine speed is reduced to zero and the problems of stability are avoided in the simulation with the GT-POWER ${ }^{\mathrm{TM}}$ software used. Figure 3 shows the implemented strategy of the engine-bypass system:
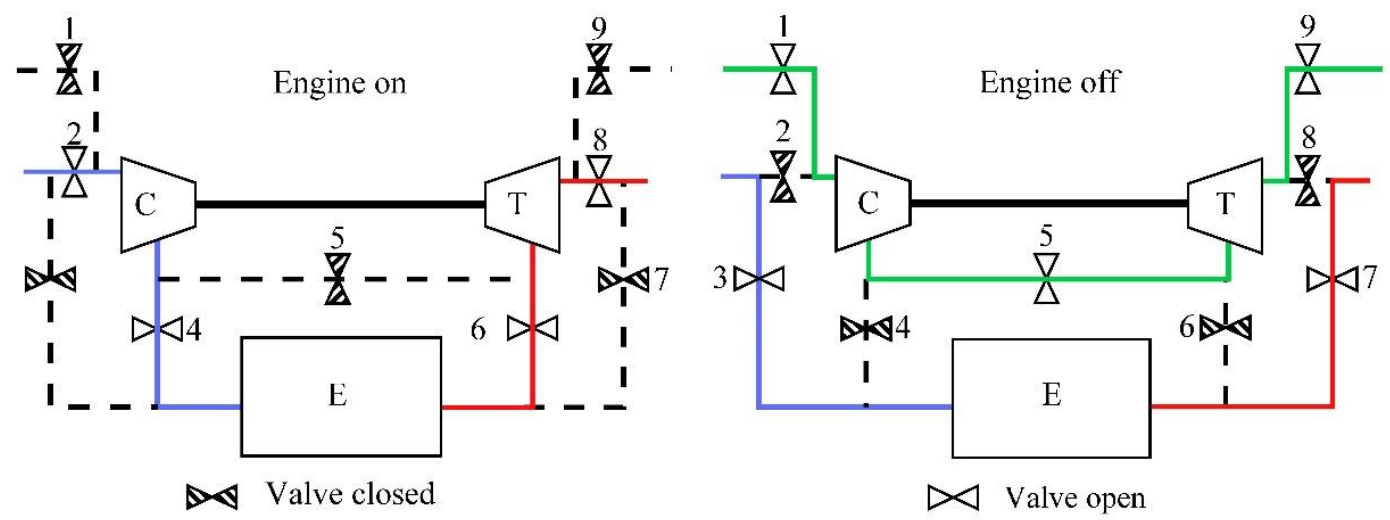

Figure 3. (a) Turbocharger bypassing strategy engine on. (b) Turbocharger bypassing strategy engine off.

Figure 3 (a) shows, when the engine is on, the turbocharger acts as a dependent element of the engine. Figure 3 (b) shows when the engine is off, then an isolation of turbine and compressor is done by closing the two, four, six and eight valves thus the turbocharger has no contact with the engine. This strategy of engine isolation as well as variations of oil and/or water mass flow is made to simulate the different phases of stationary, transient and hot-stop of an engine cycle.

Lastly, both the engine model and the turbocharger HTM were calibrated using steadystate experimental data from previous work in [26]. Unfortunately, no transient data was available for validating the unsteady results with the modelled engine and previously characterised turbocharger. It must be taken into account that to perform a rigorous comparison of the model it is necessary to know internal parameters of the turbocharger, such as geometry, material, heat transfer properties, and so on. This information is often confidential and not easy to access; indeed, it was not available to measure the turbocharger in unsteady conditions.

In an attempt to compare the performance in the HTM of the turbocharger in transient operation, data exported from a different engine were used by selecting three operating points measured under a hot stop engine cycle. Although this experimental data corresponds to a different engine and a different turbocharger, it can be used to compare the general trends. The experimental operating points for the comparison were taken into account by selecting similar turbine temperatures as in the computational campaign, ensuring the highest level of similarity between both cases. These points represent 
conditions that can be found in highway driving cycles and produce turbine inlet temperatures high enough to promote the coke formation.

From figure 4 to 6 the thermal model follows the trends of the evolution of the temperature in the different node. Axis ' $x$ ' is the elapsed time of the engine cycle, and ' $y$ ' axis represents the dimensionless temperature calculated for each node as a function of the turbine node and the compressor inlet temperatures, both values are taken at the end of the stabilisation phase, point $\mathrm{B}$ in figure 2 .

Figure 4 shows the results for a hot stop performed after a stabilisation phase at $1500 \mathrm{rpm}$ and full load. The experimental data taken are compared with the results simulated in this study using a similar value of maximum turbine temperature, in terms of dimensionless temperature $(\sigma)$ it is defined as shown in equation (1).

$$
\sigma_{i}=\left(T_{i}-T_{\min }\right) /\left(T_{\max }-T_{\min }\right)
$$

Where $T_{\max }$ represents the turbine node temperature at point $\mathrm{B}$ in figure $2, T_{i}$ the node temperature at every time instant, and $T_{\min }$ the room temperature. 

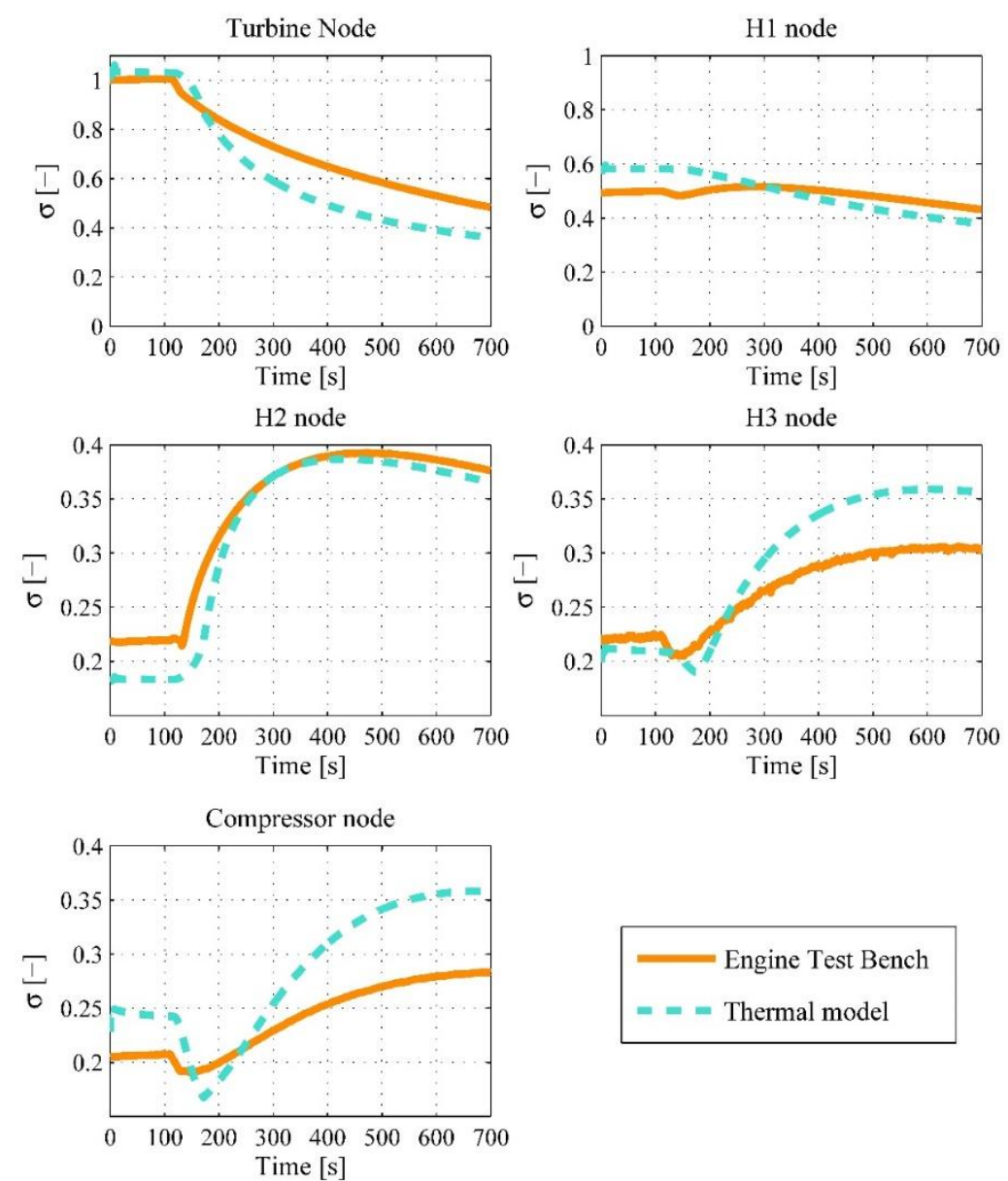

Figure 4. External turbocharger nodes comparison measured at $1500 \mathrm{rpm}$ - full load in the test bench vs initial case simulated with the thermal model

Figures 5 and 6 show same tendency but comparing other two engine operating points, one at 2500 another at 3500 having qualitatively the same tendency, as shown below. It can be seen that the turbocharger 1D model is able to compute external heat transfer between different nodes.

In steady state condition, the value in the turbine node is equal for both comparison lines the experimental and the modelled case 1. Nevertheless, final values have discernible differences, because the gas inlet temperature, the engine speed, torque and geometry are not exactly the same. In the central area of the turbocharger where the interaction with the lubrication system occurs, the difference is small. During the engine hot stop, the period of time selected allows to see the maximum level of temperature on the points in the turbocharger system. In addition, when the engine stops the turbine side, as well as node H1 (backplate turbine) loss heat due to external convection and radiation. In the compressor side, temperatures rise due to internal heat transfer through the turbocharger housing. For the central housing where $\mathrm{H} 2$ node is located the flux rise during the engine hot stop. 

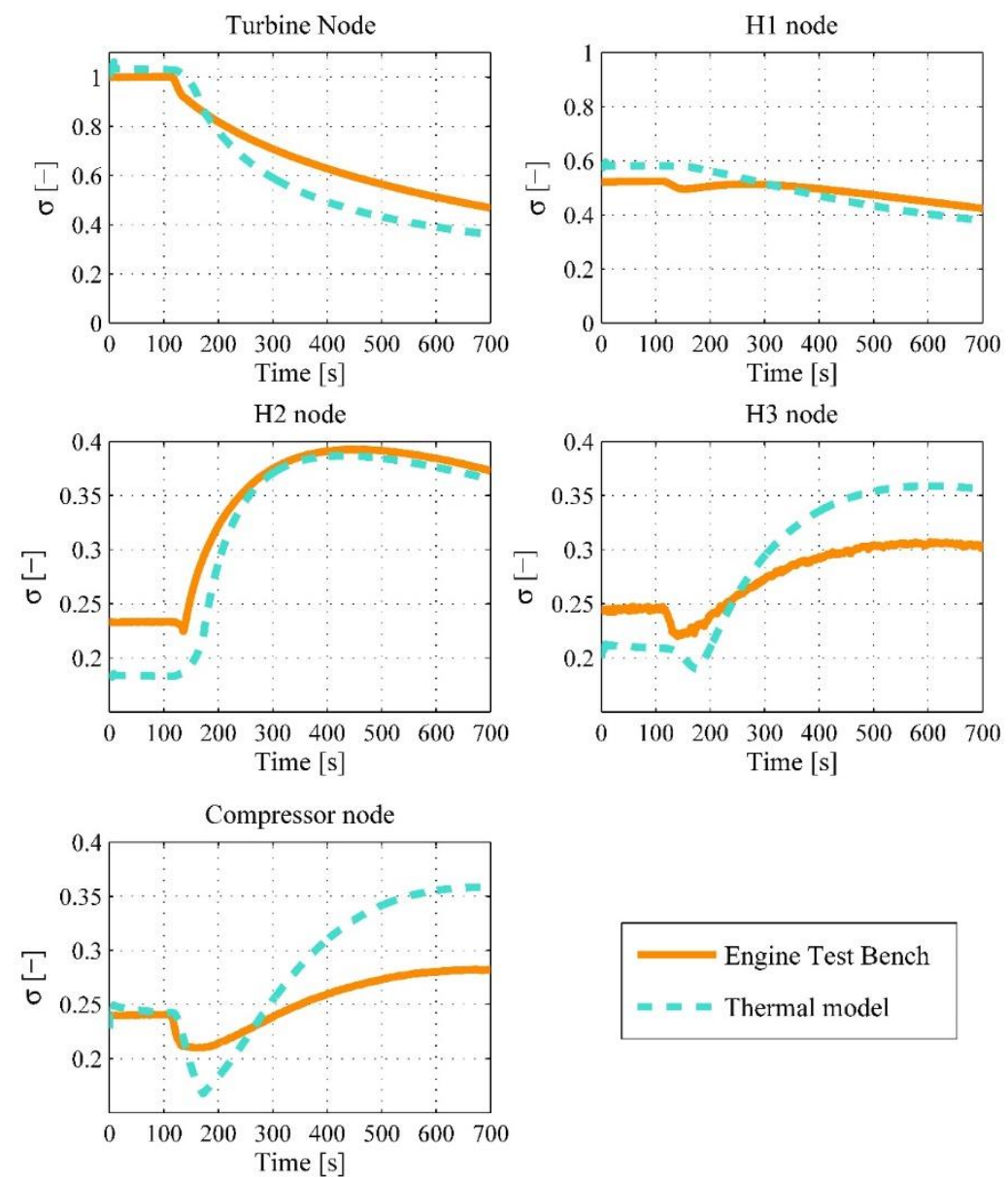

Figure 5. External turbocharger nodes comparison measured at $2500 \mathrm{rpm}-75$ percent full load in the test bench vs initial case simulated with the thermal model

The thermal model above predicts compressor node $(\mathrm{C})$ and underestimates the adjacent bearing housing node $(\mathrm{H} 3)$ temperatures during hot stop thermal transient. Apart from other small causes inherent to using a different engine and turbocharger for model assessment, one can think that heat transfer between node $\mathrm{H} 2$ and $\mathrm{H} 3$ is higher in the modelled turbocharger than in the measured one. Due to the higher values in the conductive conductance between node $\mathrm{H} 2$ and $\mathrm{H} 3$, both nodes (H3 and $\mathrm{C}$ ) show higher increments of temperature in the simulation compared to the measured. 

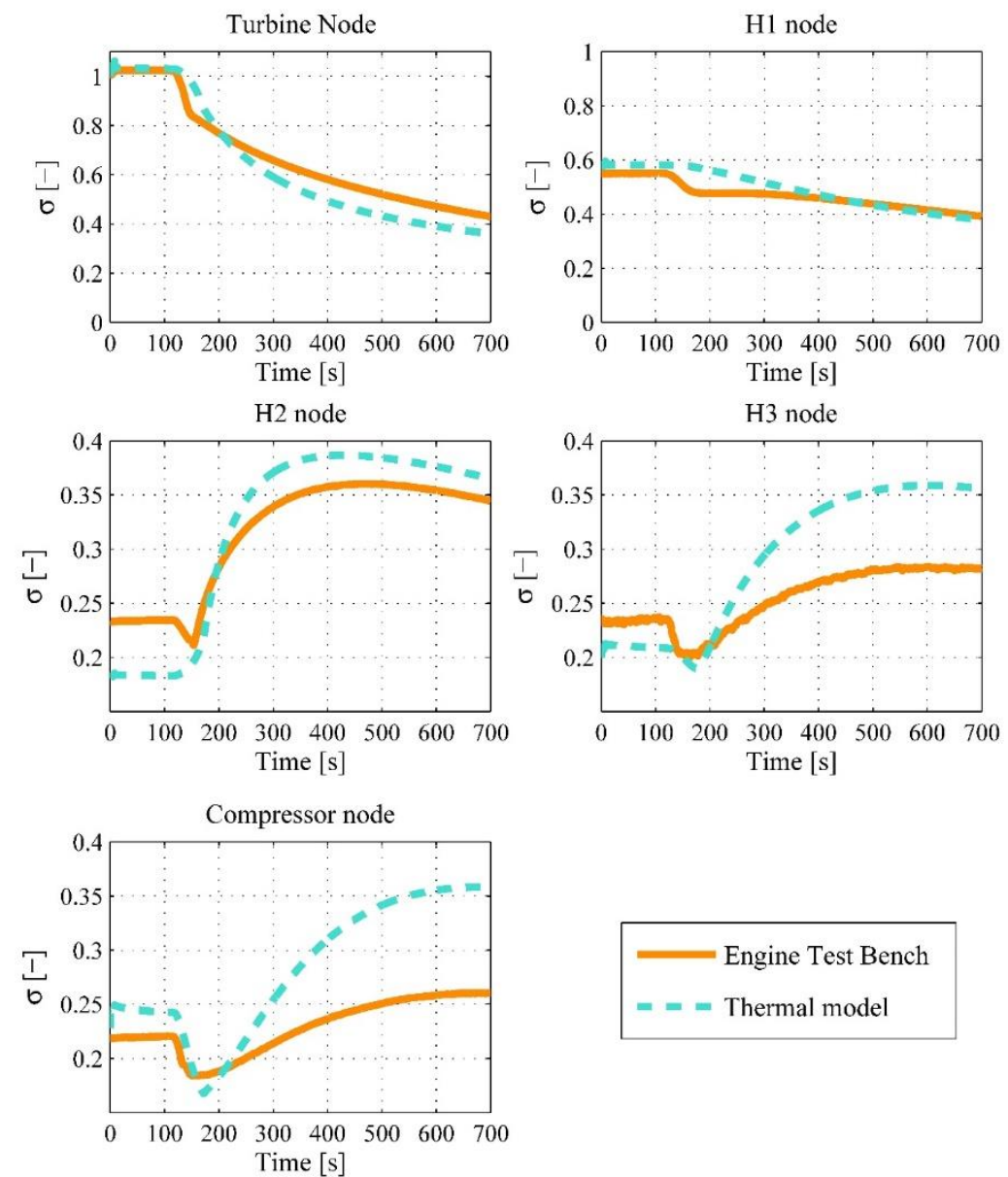

$$
\begin{array}{|l}
\hline \text { Engine Test Bench } \\
=-- \text { Thermal model }
\end{array}
$$

Figure 6. External turbocharger nodes comparison measured at $3500 \mathrm{rpm}$ - full load in the test bench vs initial case simulated with the thermal model

The differences between the experimental and the modelled engine are significant since a different engine was used to provide experimental data. This work shows in a qualitative way the trends that the model is able to reproduce under engine hot stop conditions. Both the engine and turbocharger manufacturers that know geometry, materials might feed the turbocharger model with all data so the error can be reduced. Table 2 shows differences in kelvin by comparing the temperature directly between the experimental data selected minus the baseline case 1 modelled. 
Table 2. Differences temperatures in Kelvin between experimental points and modelled case 1.

\begin{tabular}{|c|c|c|c|c|c|c|c|c|c|c|c|}
\hline \multicolumn{2}{|c|}{ Exp. Op. Point } & \multicolumn{2}{|c|}{ Turbine } & \multicolumn{2}{|c|}{ H1 } & \multicolumn{2}{|c|}{ H2 } & \multicolumn{2}{|c|}{ H3 } & \multicolumn{2}{|c|}{ Compressor } \\
\hline $\begin{array}{l}\text { Engine } \\
\text { Speed }\end{array}$ & $\mathrm{L}$ & ST & $\begin{array}{c}\text { Max } \\
\text { TR }\end{array}$ & ST & $\begin{array}{c}\text { Max } \\
\text { TR }\end{array}$ & ST & $\begin{array}{c}\text { Max } \\
\text { TR }\end{array}$ & ST & $\begin{array}{c}\text { Max } \\
\text { TR }\end{array}$ & ST & $\begin{array}{c}\text { Max } \\
\text { TR }\end{array}$ \\
\hline 1500 & 10 & -2 & 95 & -39 & 35 & 23 & 20 & 11 & 14 & -10 & 19 \\
\hline 250 & & 7 & 90 & -19 & 36 & 33 & 2 & 26 & 2 & 1 & 30 \\
\hline 3500 & 100 & 105 & 110 & 41 & 50 & 53 & 29 & 40 & 24 & 18 & 30 \\
\hline
\end{tabular}

Figure 7 shows the external nodes temperature for each selected operating point discussed in figures 4 to 6 , in point $B$ from figure 2, (just before moving on to the engine transient). In that way the temperatures evolution along with the turbocharger can analysed.
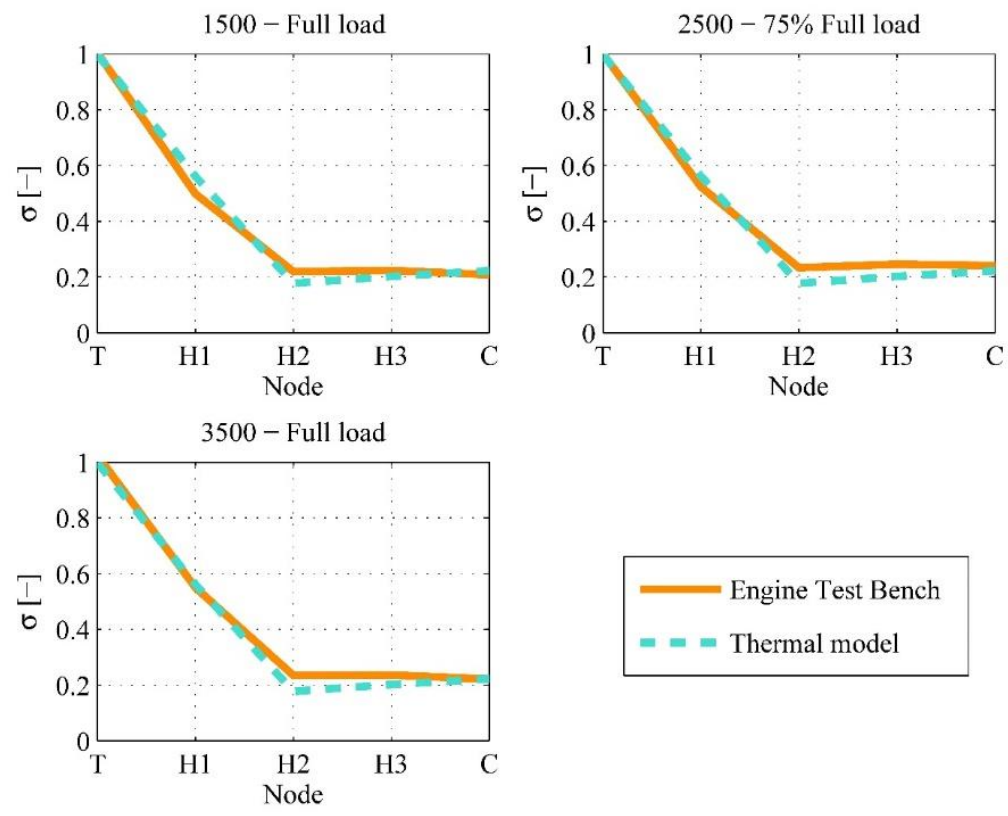

Figure 7. Turbocharger nodes comparison for three engine-operating points in stabilised phase (point B figure 2).

It can be concluded that the thermal model is able to follow the temperature gradients along with the turbocharger in each external section during the steady-state phase. Comparison of an unsteady phase about $400 \mathrm{~s}$, where the maximum temperature in the $\mathrm{H} 2$ node is reached (point $\mathrm{F}$ in figure 2) is also done (Figure 8); however, the temperature gradients differ from the measurement in a higher extent. At the compressor side, the temperatures are lower in the engine test. The temperatures of the central area of the turbocharger are equivalent for both simulations and experimental data. On the hot-end side, temperatures are higher in the turbine and $\mathrm{H} 1$ nodes for the data taken from engine bench tests. A probable reason is because this part of the turbocharger is affected by the real interaction with the radiation coming from the engine exhaust manifold that takes place a relevant role 
during the engine hot stop, while the thermal model only includes radiation phenomena between the turbocharger and the environment.
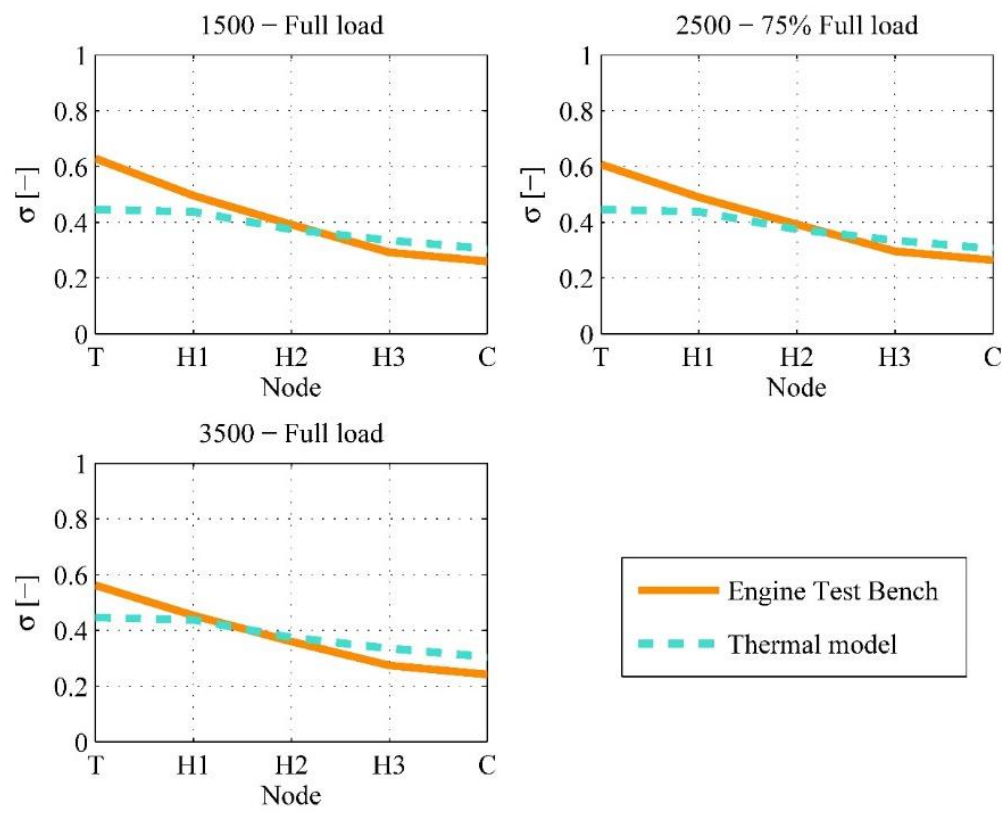

Figure 8. Turbocharger nodes comparison for three engine-operating points in transient phase (point $\mathrm{F}$ in figure 2).

After this assessment, the simulation study of the cooling strategy has been performed using a factorial analysis with four different factors acting at two different levels, leading to a total of 16 different combinations.

\section{Modelling results and discussion}

An important objective of this work is to observe the behaviour of the temperatures in the turbocharging system once the engine is shut-off, using different cooling strategies to reduce the possibilities of coke formation. The coke formation could lead to severe turbocharger damage and is produced at extremely high oil temperatures. The maximum oil temperature is expected to happen after the engine hot-stop inside the bearings and, while the turbocharger thermal model does not have the capability of computing directly this temperature, it is expected to be correlated with the bearing housing temperature, in $\mathrm{H} 1$ and $\mathrm{H} 2$ nodes, which is computed.

The factorial analysis with four different factors acting at two different levels is conducted by means of simulations. Two of the factors are the pump sizes for both the oil and coolant pumps, where the whole increase in pump size is used for increasing the flow through the turbocharger. The other two factors are the use (or not) of auxiliary, electrically driven oil and coolant pumps for the turbocharger after the engine is stopped. For this study, the adjustment of both the engine and turbocharger models during transient hot stop 
simulations were done by means of a bypassing strategy as showed in figure 3 . Therefore, in the simulation when the engine stops the cooling system for the turbocharger is cut, and no thermosiphon effects are taken into account, there is no air, water and oil circulation. Each of the nodes described in table 1 are useful for determining the local temperature of the turbocharging system for steady conditions and mainly during engine hot stop but being $\mathrm{H} 2$ the central node and representing the majority of the bearing housing material.

The simulation matrix shown in table 3, where a "-" symbol represents a low level, and a "+" symbol represents a high level in the pump size. Where $\dot{m}_{c, s i z e}$ the coolant is pump size, $\dot{m}_{o, s i z e}$ is the oil pump size. 'Yes' or 'No' means the auxiliary pump operation respectively, after engine stops either for water or oil cooling.

Table 3. Array of test for simulating the engine cycle.

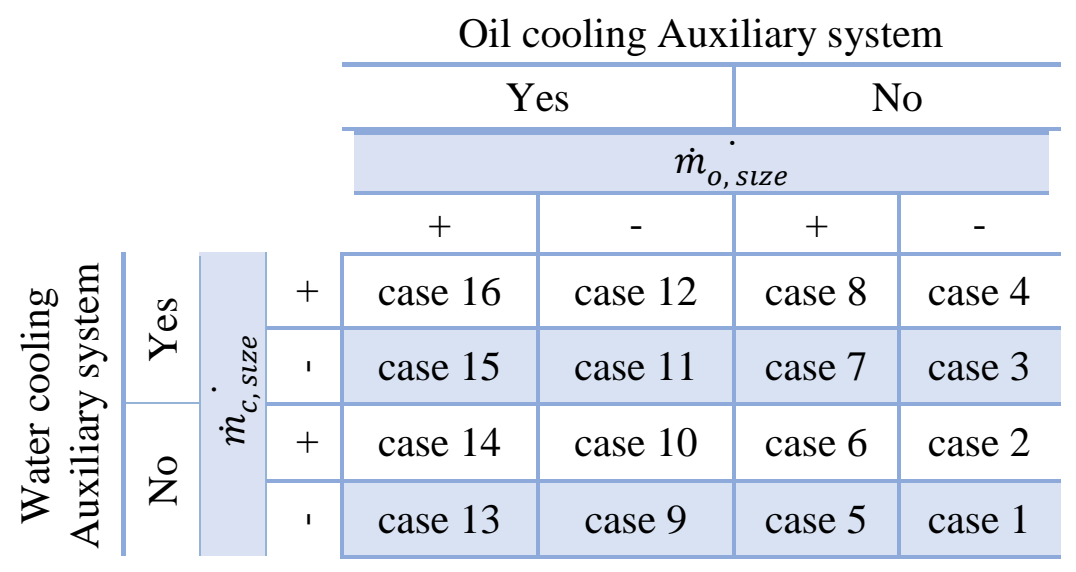

Table 4 shows the values of oil and coolant mass flow set for the different simulations carried out, and the flow value set if the auxiliary pumps are being used or not. Case 1 is taken as a baseline: it is the case with normal oil and coolant flow and no auxiliary pumps.

Table 4. Mass flow adjusted for the simulations.

\begin{tabular}{c|c|c|c|}
\multicolumn{2}{|c}{ Mass flow } & $\begin{array}{c}\text { Coolant } \\
(\mathbf{k g} / \mathbf{s})\end{array}$ & $\begin{array}{c}\text { Oil } \\
(\mathbf{k g} / \mathbf{s})\end{array}$ \\
\hline \multirow{2}{*}{ Full load } & + High & 0.15 & 0.0225 \\
\cline { 2 - 4 } & - Low & 0.1 & 0.015 \\
\hline \multirow{2}{*}{$\begin{array}{c}\text { Auxiliary } \\
\text { pump }\end{array}$} & Yes & 0.03429 & 0.00514 \\
\cline { 2 - 4 } & No & 0.0001 & 0.0001 \\
\hline
\end{tabular}

According to the initial critical case simulated, a first approximation for the auxiliary pump running time has been performed. Initially, an average $\mathrm{H} 2$ temperature can be obtained in equation (2). $T_{n}$ is the temperature at time-step $t_{n}, t_{f}$ is the specific time where maximum temperature in the central node is reached and $t_{i}$ is the time when the engine stops. 
$T_{H 2}=\sum T_{n} \cdot\left(t_{n}-t_{n-1}\right) /\left(t_{f}-t_{i}\right)$

A hypothesis of mean temperature for oil is done according to the temperature values calculated previously in order to maintain the lubrication of turbocharger under safe conditions. The convective conductance between the oil and $\mathrm{H} 2$ metal node needs to be calculated through dimensionless numbers of Reynolds, Prandtl, Nusselt and additional external geometry using proposed correlations [27] .

The convective heat transfer coefficient for the oil and water can be obtained with equation (3), where $k$ is the conductivity of the fluid and $D$ refers to the diameter of the inlet port.

$h=N u \cdot k / D$

Serrano et al. [28] have successfully correlated these convective coefficients with the turbocharger operative conditions, and the heat flux from the central housing so the heat transfer to the oil or the coolant can be easily calculated.

To obtain a real approximation of the mean oil temperature inside the turbocharger, the oil outlet temperature needs to be recalculated having a convergence with the first approximation of temperature done in equation (2).

Figure 9 shows the $\mathrm{H} 2$ and oil outlet temperatures for the case 1 shown in Table 3. The oil outlet temperature in the turbocharger can be still calculated when the engine is stopped because the mass flow rate passing is not totally null; but it is a minimum value very close to zero, equivalent to the small amount of oil dripping naturally present after halting the oil pump.
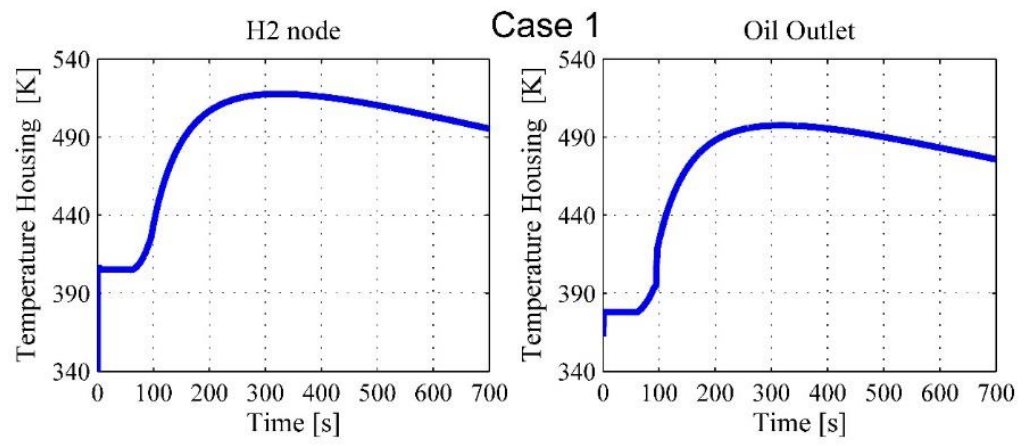

Figure 9. H2 node and oil outlet temperature for the baseline case.

Finally equation (4) represents the integral of the heat flow already calculated, which can be used to estimate the acting time for the auxiliary pump system. $C$ is the sum of all capacitances of the five metal nodes of the turbocharger thermal, obtained experimentally [27,29], and $\Delta T$ is the temperature decrease from an initial case simulated that lack of any type of extra cooling after the hot-stop.

$\int \dot{Q} d t=C \cdot \Delta T$ 
For a reduction of $25^{\circ} \mathrm{C}$ in the average turbocharger temperature, used in order to keep the oil under safe conditions [30], the additional operating time for an auxiliary oil pump after the engine stops is approximately 2.23 minutes; the water cooling pump would need less time. For the sake of simplicity, the electric auxiliary pumping system is left acting for 2 minutes for both water and oil strategies.

Once the pump operating time has been determined, the other tests from Table 3 have been carried out to see the thermal evolution of the turbocharger under different cooling strategies.

Figure 10 shows the representative simulation results for four different cases of cooling strategy, from Table 3. The turbine node has a peak temperature of $858 \mathrm{~K}$ followed by a drop in temperature once the engine is stopped, while the other nodes reach their maximum temperature later. The compressor side or the $\mathrm{H} 3$ node reach maximum temperatures more than $60 \mathrm{~K}$ higher than when the engine is operating at high loads.

At the end of the simulation all the nodes reach convergence with a temperature between $484 \mathrm{~K}$ and $494 \mathrm{~K}$.

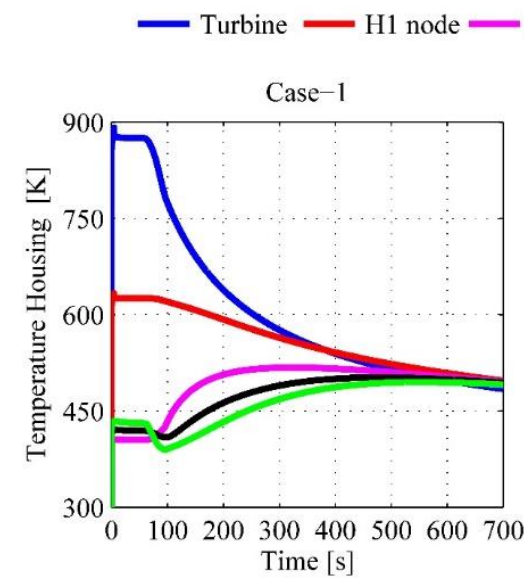

$\mathrm{H} 2$ node $-\mathrm{H} 3$ node - Compressor
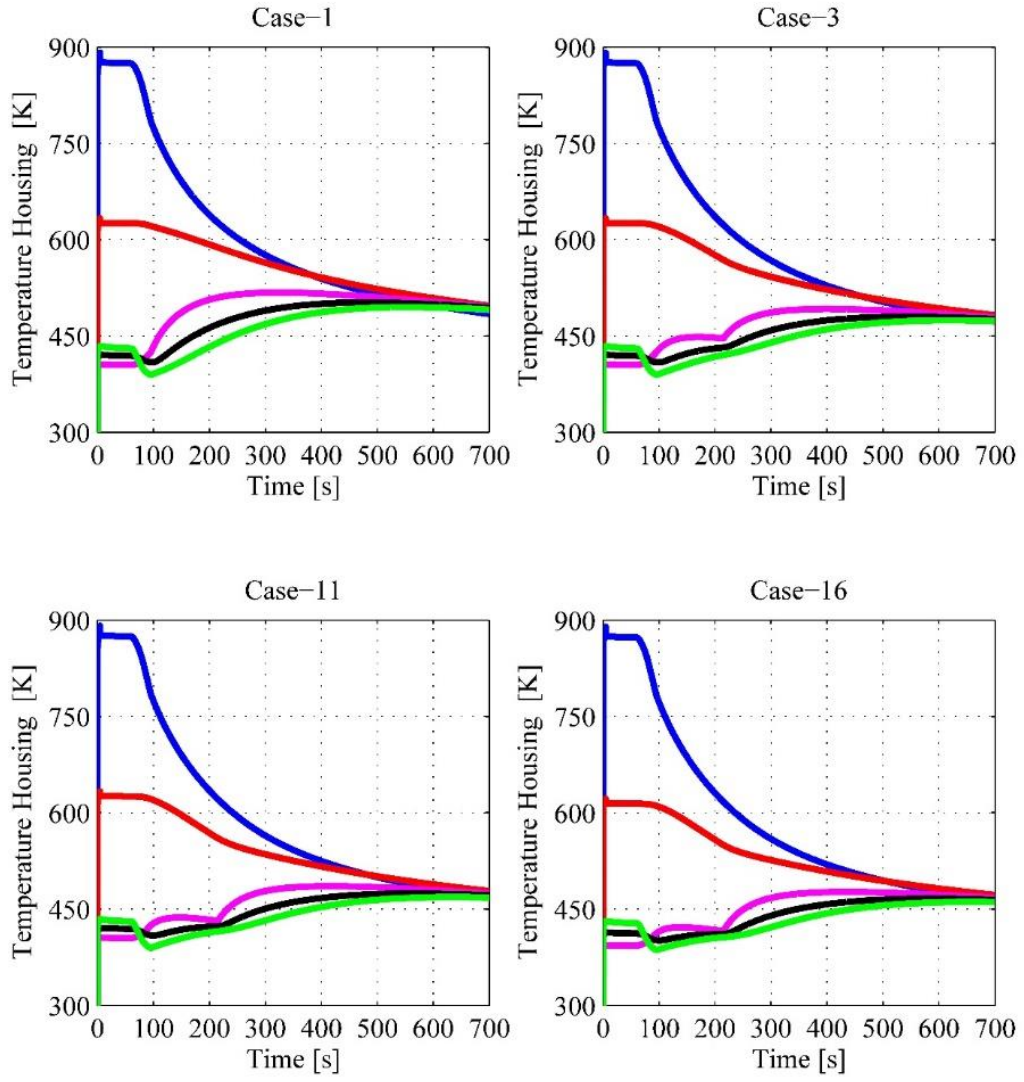

Figure 10. Most representative turbocharger temperatures from simulation array. 
For this study the analysis of possible failure or loss of efficiency during hot-stop, from the thermal point of view, is focused on the evolution of the H1 node temperature, where the highest central housing temperature is achieved. As well as the $\mathrm{H} 2$ node temperature, which represents the majority of the central housing mass and handles the biggest part of the oil flow.

During the simulations, the maximum gas inlet temperature was $1100 \mathrm{~K}$. In Figure 11 there is an evolution of temperatures in $\mathrm{H} 1$ metal node which is the contact node with the greatest hot spot from the turbine side, where the hot exhaust gases are released. During the engine throttle tip-out phase, the gas temperature is reduced as the amount of fuel injected is decreased up to zero. The differences between the different cooling strategies are not so small if we group the different cases. Clearly cases 1,2,5,6 show higher temperature than the others since no auxiliary pumps are considered.
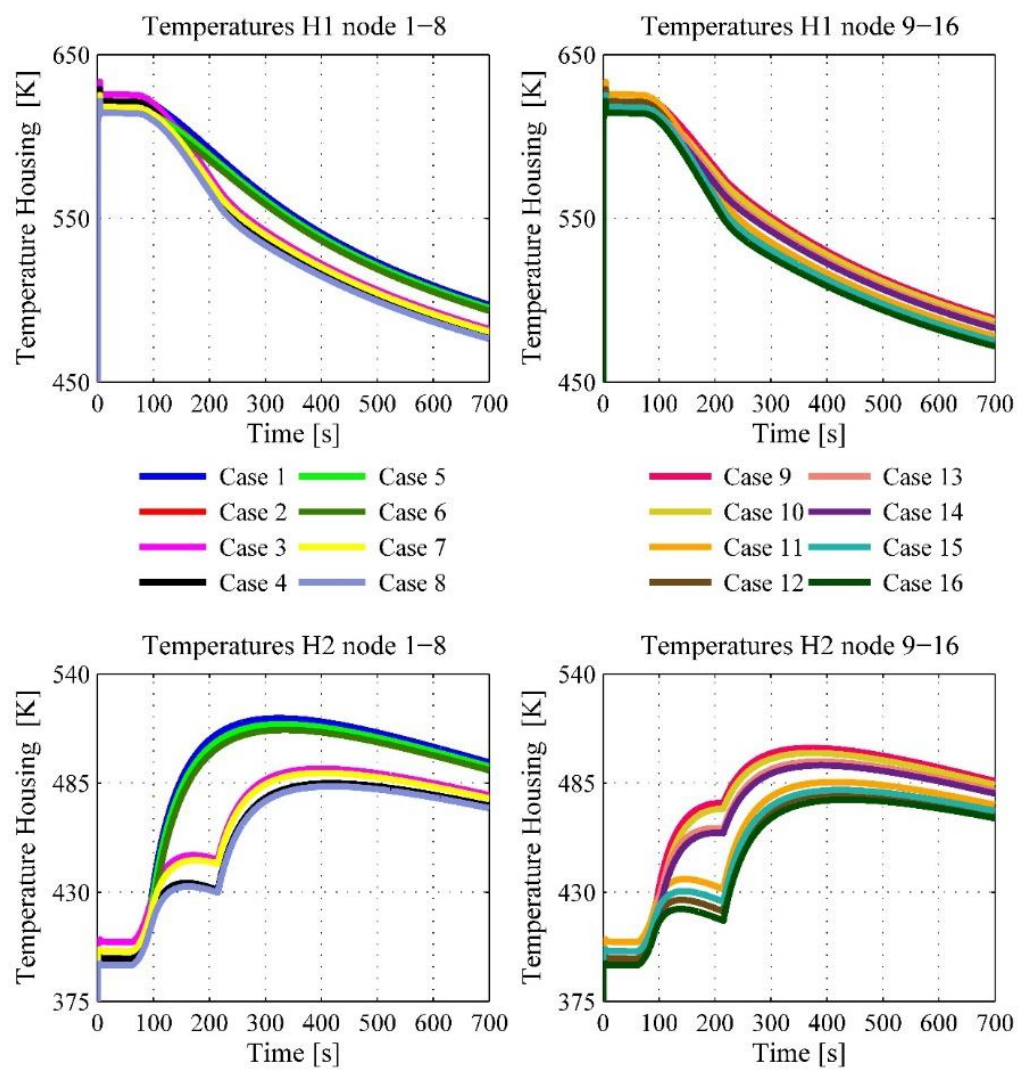

Figure 11. Evolution of temperatures in $\mathrm{H} 1$ and $\mathrm{H} 2$ metal nodes for all simulation cases.

Figure 11 shows clear differences in the $H 2$ metal node behaviour for the different cooling strategies. During cases 1, 2, 5 and 6, temperatures are maximum because of the auxiliary pumps are not operated. In addition, the differences in maximum peak temperature and the time needed are small between these cases. For the other cases, the behaviour is similar between them since the movement of water or oil is still running for about two minutes 
after the engine is stopped. When the cooling supply is switched off, the evolution of temperatures are rising and tend to be similar to those from the 1, 2, 5 and 6 group but the maximum temperatures from this group are never reached because of the heat loss. It can also be seen than water cooling auxiliary pump is more effective than oil pump. The lack of auxiliary oil pump does not affect much to the temperature control, as shown in cases 3 , 4, 7, and 8 from Figure 11.

The observed response indicates that the specific energy consumption during a whole driving and hot stop cycle by both the oil and coolant pumps can be minimized for a temperature objective by choosing a proper cooling strategy. This specific energy consumption is expressed as the amount of energy consumed by the pumps divided by the drop in maximum node $\mathrm{H} 2$ temperature. Case 1 is used as a baseline for comparisons. The maximum oil temperature inside the bearing system is unknown, but it should be correlated with the bearing housing temperature (as shown in Figure 9), a reduction in maximum $\mathrm{H2}$ temperature should lead to a reduction in maximum oil temperature and thus, the coke formation.

The results about temperature drop are shown in table 5. The highest temperature drop is obtained with the combination of high flow rates of oil and coolant during normal operation of the engine and also by operating the auxiliary pumps as expected.

Table 5. Delta temperature decrease in H2 metal node.

\begin{tabular}{|c|c|c|c|c|c|c|}
\hline \multirow{3}{*}{\multicolumn{3}{|c|}{$\begin{array}{c}\text { H2 } \Delta T \\
\text { DECREASE } \\
(\mathrm{K})\end{array}$}} & \multicolumn{4}{|c|}{ Oil Cooling } \\
\hline & & & \multicolumn{2}{|c|}{ Yes auxiliary system } & \multicolumn{2}{|c|}{ No auxiliary system } \\
\hline & & & + & - & + & - \\
\hline \multirow{5}{*}{ 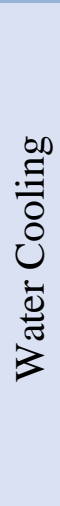 } & \multirow{2}{*}{ 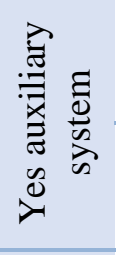 } & + & $\begin{array}{c}\text { case } 16 \\
41\end{array}$ & $\begin{array}{c}\text { case } 12 \\
38\end{array}$ & $\begin{array}{c}\text { case } 8 \\
34\end{array}$ & $\begin{array}{c}\text { case } 4 \\
33\end{array}$ \\
\hline & & 1 & $\begin{array}{c}\text { case } 15 \\
36\end{array}$ & $\begin{array}{c}\text { case } 11 \\
32\end{array}$ & $\begin{array}{c}\text { case } 7 \\
28\end{array}$ & $\begin{array}{c}\text { case } 3 \\
26\end{array}$ \\
\hline & \multirow{3}{*}{ 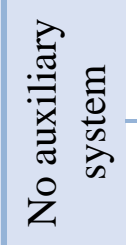 } & + & case 14 & case 10 & case 6 & case 2 \\
\hline & & & 24 & 18 & 6 & 3 \\
\hline & & 1 & $\begin{array}{c}\text { case } 13 \\
22\end{array}$ & $\begin{array}{c}\text { case } 9 \\
15\end{array}$ & $\begin{array}{c}\text { case } 5 \\
3\end{array}$ & $\begin{array}{c}\text { case } 1 \\
0\end{array}$ \\
\hline
\end{tabular}

The power consumption of the pumps is approximated by a linear relationship with the fluid flow rates, taking into account only the requirements for the turbocharger. In the case of the coolant pump, the power consumption is around $25 \mathrm{~W}$ for typical flow rates of around $0.15 \mathrm{~kg} / \mathrm{s}$, whereas for the oil pump the power consumption is around $60 \mathrm{~W}$ for typical flow rates around $0.015 \mathrm{~kg} / \mathrm{s}$. The specific energy consumed during the simulated cycles is shown in table 6. The specific $\mathrm{CO} 2$ emissions are estimated for a diesel engine with an average engine efficiency of $33 \%$. 
As shown in table 6; the optimum results, in terms of energy consumption per $\mathrm{K}$ of $\mathrm{H2}$ temperature decrease, are obtained with the original pumps and using an auxiliary coolant pump after the engine stops (case 3). Worse results are obtained in all the cases by using bigger oil pump, as it consumes more energy and the effect is not big. When using both auxiliary pump, (case11) the decrease in maximum $H 2$ temperature is higher, but the specific energy consumption rises faster than when using only the coolant pump (case 3 ). However, the differences between the results of the auxiliary pumps and the increase in $\mathrm{CO} 2$ emissions are small in both cases. It is worth noting that in the case of an oil-cooled turbocharger, the auxiliary oil pump solution is expected to generate oil leakages if any new oil sealing technology is used.

Table 6. Extra specific consumption and emissions for the sixteen cases simulated.

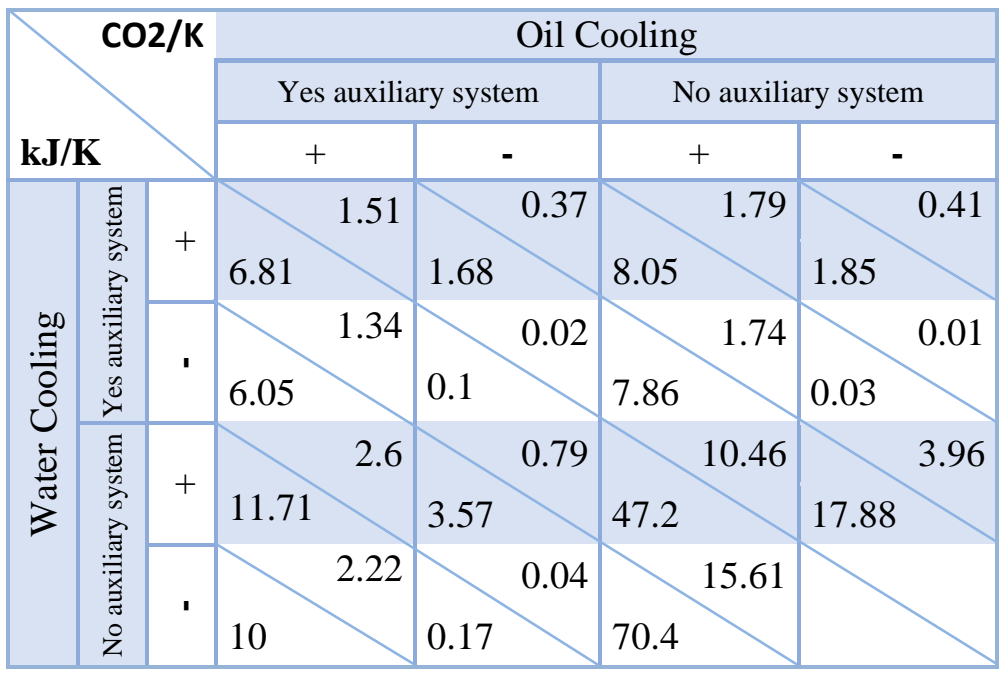

The calculated specific energy consumption associated with this cooling method is maximised when a normal cooling strategy in combination with a big oil pump has been modelled. The auxiliary water-cooling pump seems to produce the optimum results in terms of specific energy consumption, as it has more cooling capacity with less power consumption than the oil pump. 


\section{Conclusions}

Different cooling strategies have been simulated in order to minimise the possibility of thermal damage and coke formation inside the bearing housing of an automotive turbocharger under hot-stop engine cycle while keeping the associated fuel consumption to this cooling strategies as low as possible. The applied turbocharger heat transfer model considers the mass flow at the compressor, turbine, lubrication and cooling system and is able to calculate the temperature of the metal in each section in order to predict the mean temperatures of exhaust gas and air as flowing in turbocharger.

The heat transfer model is coupled to a full engine simulation performed in GT-POWER. A nine-valve bypass system is used to solve some stability issues in the engine model that were found during the simulations when its speed was close to 0 . In this way, it was possible to study thermal transients in the turbocharger bearing housing during hot stops.

Adjusting the bypassing strategy for the management of the engine hot-stop in the simulations, the turbocharger model calculates the main performance variables of the compressor and the turbine, also computing the main heat fluxes.

The engine model and the turbocharger HTM were calibrated and validated in previous works, although not during engine hot-stops. There were experimental data available for a different turbocharger and engine in hot-stops, but not enough to calibrate a whole engine model, these data were used to get general thermal trends. They were qualitatively compared to those of the calibrated engine and turbocharger models, showing similar behaviour. Although the results are promising, more work is needed to perform a full validation of the model with turbocharger thermal data during hot-stops.

According to the simulations performed, the heat transfer to the oil reduces to almost 0 when the engine stops. As a consequence, the sudden stop of cooling power will cause an important increase of bearing housing temperature due to its internally accumulated energy that cannot be released. Two main variables have been studied: the temperature of the turbine back plate of the bearing housing ( $\mathrm{H} 1$ node) and the temperature of the turbocharger central bearing housing ( $\mathrm{H} 2$ node). In the black plate turbine (H1 node) the temperature steadily drops after the engine stops, but for $\mathrm{H} 2$ node, peak temperature is reached at almost four minutes after the engine stops in the baseline case (normal oil and coolant flow rates, but no auxiliary pumps operating after the engine stops). $H 1$ node is just a bit less sensible than $\mathrm{H} 2$ for the different cooling methods.

Thermal transient study shows good overall results in the turbocharger metal nodes temperatures but further research is needed if the temperature of the oil trapped inside the bearings has to be computed. Nevertheless, this fact should not affect the conclusions of this work since the trapped oil temperature should show a clear correlation with $H 1$ and H2 temperatures.

Peaks of temperature in the central bearing housing ( $H 2$ node) seem to be relatively insensitive to pump size when there are no auxiliary pumps. The calculated specific energy 
consumption is associated with this cooling method thoroughly when a normal cooling strategy in combination with a big oil pump has been modelled. The improvement in $H 2$ temperature drop is produced with a big energy consumption and $\mathrm{CO} 2$ production when compared with the results of normal-sized pumps.

The auxiliary water cooling pump seems to produce the optimum results in terms of specific energy consumption as it has more cooling capacity with less power consumption than the oil pump. The operation of the auxiliary pump not only does reduce the peak $H 2$ temperature, but also produces this temperature peak between one and two minutes later.

\section{Acknowledgments}

We thank Przemek Kmieć for his support in the language editing. This work has been partially supported by the Spanish Ministry of Economy and Competitiveness through [grant No. TRA2013-40853-R].

\section{Bibliography}

[1] J.B. Heywood, Internal Combustion Engine Fundamentals, 1988.

[2] R.-R.H.T. Taylor, Douglas Richard, Boxkite to Jet: The Remarkable Career of Frank B.Halford (Historical), 1999.

[3] E. Watel, A. Pagot, P. Pacaud, J. Schmitt, Matching and Evaluating Methods for Euro 6 and Efficient Two-stage Turbocharging Diesel Engine, SAE Tech. Pap. (2010). doi:10.4271/2010-01-1229.

[4] D. Polichronis, R. Evaggelos, G. Alcibiades, G. Elias, P. Apostolos, Turbocharger Lubrication - Lubricant Behavior and Factors That Cause Turbocharger Failure, Int. J. Automot. Eng. Technol. 2 (2013) 40-54.

[5] D. Deng, F. Shi, L. Begin, I. Du, General Motors, The Effect of Oil Debris in Turbocharger Journal Bearings on SubSynchronous NVH, SAE Int. 2015-01-12 (2015). doi:10.4271/2015-01-1285.

[6] M.F. Moreira, Failure analysis in aluminium turbocharger wheels, Eng. Fail. Anal. 61 (2016) 108-118. doi:10.1016/j.engfailanal.2015.11.024.

[7] J. Galindo, J.R. Serrano, C. Guardiola, C. Cervelló, Surge limit definition in a specific test bench for the characterization of automotive turbochargers, Exp. Therm. Fluid Sci. 30 (2006) 449-462. doi:10.1016/j.expthermflusci.2005.06.002.

[8] J.T. Gravdahl, O. Egeland, S.O. Vatland, Drive torque actuation in active surge control of centrifugal compressors, Elsevier Autom. 38 (2002) 1881-1893. doi:10.1016/S00051098(02)00113-9.

[9] M. Skopil, T. Bulaty, Calculation of compressor surge with unsteady flow model, IMechE. (1998) 219-226. https://getinfo.de/de/suchen/id/BLCP\%3ACN027831572/Calculation-ofcompressor-surge-with-unsteady-flow/ (accessed September 15, 2015).

[10] J. Galindo, J.M. Luján, J.R. Serrano, V. Dolz, S. Guilain, Description of a heat transfer model suitable to calculate transient processes of turbocharged diesel engines with onedimensional gas-dynamic codes, Appl. Therm. Eng. 26 (2006) 66-76.

doi:10.1016/j.applthermaleng.2005.04.010. 
[11] R.D. Burke, C.R.M. Vagg, D. Chalet, P. Chesse, Heat transfer in turbocharger turbines under steady, pulsating and transient conditions, Int. J. Heat Fluid Flow. 52 (2015) 185197. doi:10.1016/j.ijheatfluidflow.2015.01.004.

[12] J.R. Serrano, B. Tormos, K.L. Gargar, F. Bouffaud, Study of the Effects on Turbocharger Performance Generated by the Presence of Foreign Objects at the Compressor Intake, Exp. Tech. 37 (2013) 30-40. doi:10.1111/j.1747-1567.2011.00795.x.

[13] J. Galindo, J.R. Serrano, V. Dolz, M.A. López, Behavior of an IC Engine Turbocharger in Critical Condition of Lubrication, SAE Int. J. Engines. 6 (2013) 797-805. doi:10.4271/2013-01-0921.

[14] J.R. Serrano, P. Olmeda, A. Tiseira, L.M. Garcia-Cuevas, A. Lefebvre, Theoretical and experimental study of mechanical losses inautomotive turbochargers, Energy. 55 (2013) 888-898. doi:10.1016/j.energy.2013.04.042.

[15] M. Deligant, P. Podevin, G. Descombes, CFD model for turbocharger journal bearing performances, Appl. Therm. Eng. 31 (2011) 811-819. doi:10.1016/j.applthermaleng.2010.10.030.

[16] H.C. Lin, Y.T. Chang, G.L. Tsai, D.M. Wang, F.C. Hsieh, J.F. Jiang, Oil Coking Prevention Using Electric Water Pump for Turbo-Charge Spark-Ignition Engines, Hindawi Publ. Corp. 2014 (2014) 9. doi:Artn 498624\rDoi 10.1155/2014/498624.

[17] H. Aghaali, H.-E. Å Ngströ M, J.R. Serrano, Evaluation of different heat transfer conditions on an automotive turbocharger, Int. J Engine Res. 16 (2015) 137-151. doi:10.1177/1468087414524755.

[18] I. Miyata, S. Hirano, M. Tanada, K. Fujimoto, Mechanism of Turbocharger Coking in Gasoline Engines, SAE Int. (2015) 1-15. doi:10.4271/2015-01-2029.

[19] R.D. Burke, C.J. Brace, R. Stark, I. Pegg, Investigation into the benefits of reduced oil flows in internal combustion engines, Int. J. Engine Res. (2015).

[20] J.R. Serrano, P. Olmeda, F.J. Arnau, A. Dombrovsky, L. Smith, Analysis and Methodology to Characterize Heat Transfer Phenomena in Automotive Turbochargers, J. Eng. Gas Turbines Power. 137 (2015) 1-11. doi:10.1115/1.4028261.

[21] R.D. Burke, Analysis and Modeling of the Transient Thermal Behavior of Automotive Turbochargers, J. Eng. Gas Turbines Power. 136 (2014) 101511. doi:10.1115/1.4027290.

[22] D.P.D. Theodore L Bergman, Adriennne S. Lavine, Frank P. Incropera, Fundamentals of Heat and Mass Transfer, 2011. doi:10.1016/j.applthermaleng.2011.03.022.

[23] V. Simon, G. Oberholz, M. Mayer, Exhaust gas temperature $1050^{\circ} \mathrm{C}$ An engineering challenge, BorgWarner TurboSystems Acad. (2000) 1-12.

[24] A.K. Sachdev, K. Kulkarni, Z.Z. Fang, R. Yang, V. Girshov, Titanium for automotive applications: Challenges and opportunities in materials and processing, Jom. 64 (2012) 553-565. doi:10.1007/s11837-012-0310-8.

[25] I. Brahma, Analysis and prediction of transient opacity spikes using dimensional modeling, Int. J. Engine Res. 15 (2013) 263-281. doi:10.1177/1468087413475807.

[26] J. Serrano, P. Olmeda, F.J. Arnau, A. Dombrovsky, L. Smith, Turbocharger heat transfer and mechanical losses influence in predicting engines performance by using onedimensional simulation codes, Energy. 86 (2015) 204-218. doi:10.1016/j.energy.2015.03.130.

[27] J. Serrano, P. Olmeda, F. Arnau, A. Dombrovsky, General Procedure for the 
Determination of Heat Transfer Properties in Small Automotive Turbochargers, SAE Int. J. Engines. (2014) 12. doi:10.4271/2014-01-2857.

[28] J. Serrano, P. Olmeda, F.J. Arnau, M. a. Reyes-Belmonte, H. Tartoussi, A study on the internal convection in small turbochargers. Proposal of heat transfer convective coefficients, Appl. Therm. Eng. 89 (2015) 587-599. doi:10.1016/j.applthermaleng.2015.06.053.

[29] M. Angel, R. Belmonte, Contribution to the Experimental Characterization and 1-D Modelling of Turbochargers for IC Engines, 2013.

[30] E.G. Ribeiro, W.B. Melo, A.P. a. Filho, Application of electric oil pumps on automotive systems, SAE Int. J. Engines. 1 (2005) 1-7. doi:10.4271/2005-01-4086.

\section{Notation}

$\mathrm{C}:$ Heat capacity $(\mathrm{J} / \mathrm{K})$

$C$ : Compressor housing node from the heat transfer model

$D$ : Diameter (m)

E : Engine

$E$ : Energy consumed for decreasing the temperature of the $\mathrm{H} 2$ node

EURO 6 : European emission standards for light passenger and commercial vehicles

Exp: Experimental

GT-POWER: Commercial tool of wave action for modelling each of the most important components of a real engine

$h$ : Convective heat transfer coefficient $\left(\mathrm{W} /\left(\mathrm{m}^{2} \mathrm{~K}\right)\right.$

$H 1$ : Turbine back plate node from the heat transfer model

$H 2$ : Turbocharger central housing node from the heat transfer model

$H 3$ : Compressor back plate node from the heat transfer model

HTM : Heat transfer model

IT : Turbine Inlet Temperature $(\mathrm{K})$

$k$ : Thermal conductive coefficient $(\mathrm{W} / \mathrm{m} \mathrm{K})$

$\dot{m}$ : Mass flow $(\mathrm{kg} / \mathrm{s})$

NOx: nitrogen oxides produced during combustion

$\mathrm{Nu}$ : Nusselt number

OC : Compressor outlet temperature $(\mathrm{K})$

OD : Outlet Diffusor from the heat transfer model

OI : Oil inlet from the heat transfer model

OO : Oil outlet from the heat transfer model

Op: Operating

OT : Turbine outlet temperature from the heat transfer model

$\dot{Q}$ : Heat flow (J) 
S : Specific entropy $(\mathrm{J} / \mathrm{kg} \mathrm{K})$

$t:$ Time (s)

$\mathrm{T}$ : Turbine housing node from the heat transfer model

$T$ : Temperature (K)

$W:$ Water node from the heat transfer model

$\mathrm{W}:$ Power $(\mathrm{W})$

$\Delta T$ : Delta temperature $(\mathrm{K})$

$\sigma:$ Dimensionless temperature $\quad \sigma_{i}=\frac{T_{i}-T_{\min }}{T_{\max }-T_{\min }}$

\section{Subscripts}

$p:$ Specific heat capacity at constant pressure $(\mathrm{J} / \mathrm{kg} \mathrm{K})$

$c$, size: Coolant pump size factor- mass flow $(\mathrm{kg} / \mathrm{s})$

$o$, size: Oil pump size factor- mass flow $(\mathrm{kg} / \mathrm{s})$

mech: Mechanical losses from the heat transfer model

$i$ : Time when the engine stops

$f$ : Specific time where maximum temperature in $\mathrm{H} 2$ central node is located (s)

$n$ : Period of time between the engine stops and the oil maximum temperature reached (s)

H2: Mean of oil temperature in the central node (K) 